\title{
Book Review: Analyzing Social Media Networks with NodeXL - Insights from a Connected World
}

\author{
Aras Bozkurt \\ Anadolu University, Turkey
}

\begin{abstract}
Introduction
The book "Analyzing Social Media Networks with NodeXL: Insights from a Connected World" was authored by Derek L. Hansen, Ben Shneiderman, and Marc A. Smith. It was published in 2011 by Morgan Kaufmann-Elsevier, Burlington, Massachusetts, USA. The online edition of the book has a total of $284+x$ vages. The ISBN of the book is 978-0-12-382229-1.
\end{abstract}

For centuries, individuals have lived only in the physical world and confined themselves to the boundaries of that world. However, the advent of computers, Web, and the Internet has led to another reality - the reality of digital and virtual worlds. This transformation has extended networks beyond the limits of the physical world. The result is networked societies (Castells, 2004), networked individuals (Rainie and Wellman, 2012), social network theory (Scott, 2000), and as a new research paradigm (Bozkurt, Akgun-Ozbek, \& Zawacki-Richter, 2017) social network analysis (Hansen, Shneiderman, \& Smith, 2011).

Almost the entire world is now connected and networks are everywhere - from biological networks to infrastructure networks; from knowledge networks to social networks. Some networks are visible, while other networks are invisible. Similarly, while some nodes and ties among them are visible, some of them invisible. Some of the networks have clear borders, while some have blurred borders making it difficult to say where one starts and one ends. A network can be a cluster or just another node within a greater network. In sum, the whole world - with all living and non-living entities - is part of a network and networks are complex structures.

A node can be a living or non-living entity. The interactions, relationships or links among these nodes define ties. In essence, every network is the sum of nodes and ties among them. In physical networks, it is difficult to track nodes and identify ties among them, especially when the scale is greater. While it is possible to track, identify and map physical networks, this possibility is limited in time, space and human capability. However, the ability to track and identify nodes and ties among them on digital networks is possible because every single click leaves a digital trace and we can track, identify, collect, and analyze these digital traces. In this context, social network analysis provides techniques, tools and approaches to practice social networking, while social network theory provides the conceptual background to interpret the network data.

This is where this book steps in and provides a systematic walkthrough for those interested in social network analysis. With a special focus on social networking in digital networked spaces, "Analyzing Social Media Networks with NodeXL: Insights from a Connected World" explains how to practice social network analysis by using NodeXL software. 


\section{Organization of the Book}

The book explains social network analysis by providing examples from NodeXL, which operates as a plugin for Microsoft Excel. It is organized in three parts, amounting to a total of 15 chapters. The first part provides explanations about the history and core concepts of social media and social network analysis. The second part provides examples, explanations and practices using NodeXL software. The third part focuses on subdomains of social network analysis. Each chapter contains sections on the practitioner's summary and researcher's agenda. The overall organization of the book as follows:

Part I, Getting Started with Analyzing Social Media Networks describes what SNA is and then explains core concepts.

- Chapter 1, Introduction to Social Media and Social Networks provides a general overview of social media, social networks and network science.

- Chapter 2, Social Media: New Technologies of Collaboration is about well-known social media tools and services that support social interaction between users.

- Chapter 3, Social Network Analysis: Measuring, Mapping, and Modeling Collections of Connections introduces core concepts and ideas of social network analysis and visualization.

Part II, NodeXL Tutorial: Learning by Doing focuses on practicing SNA using NodeXL.

- Chapter 4, Getting Started with NodeXL, Layout, Visual Design, and Labeling introduces the basics of NodeXL software, especially designed to perform social network analysis with visualization.

- Chapter 5, Calculating and Visualizing Network Metrics introduces local and global metrics and tips about how to visualize networks.

- Chapter 6, Preparing Data and Filtering explains how to cleanse or modify data sets to improve the quality of analysis and introduces different strategies for analyzing large network data sets.

- Chapter 7, Clustering and Grouping examines approaches to analyzing network data, considering that networks are a complex combination of smaller groups or subgraphs.

Part III, Social Media Network Analysis Case Studies provides specific cases and explains how to implement SNA in these cases.

- Chapter 8, Email: The Lifeblood of Modern Communication is about one of the most widely used communication methods, e-mail, and applies social network analysis.

- Chapter 9, Thread Networks: Mapping Message Boards and Email Lists focuses on examples of asynchronous threaded conversation platforms.

- Chapter 10, Twitter: Conversation, Entertainment, and Information, All in One Network! focuses on one of the most popular microblogging services, Twitter, and uses social network analysis for this type of network. 
- Chapter 11, Visualizing and Interpreting Facebook Networks provides a general outlook of Facebook and guides readers on how to conduct social network analysis on this social networking site.

- Chapter 12, WWW Hyperlink Networks is about the largest machine-readable network: The World Wide Web. Unlike previous chapters, this chapter focuses on lessons that can be learned from exploring the hyperlink network alone.

- Chapter 13, Flickr: Linking People, Photos, and Tags looks at one of the most widely used image-sharing social network sites and presents several examples to demonstrate how to conduct social network analysis of it.

- Chapter 14, YouTube: Contrasting Patterns of Content, Interaction, and Prominence introduces the network structure and dynamics of YouTube and then provides examples of how to carry out social network analysis on this site.

- Chapter 15, Wiki Networks: Connections of Creativity and Collaboration is about another popular Web 2.0 service, Wikis, and introduces examples to give insights on how to conduct social network analysis in wiki services.

\section{Conclusion}

"Analyzing Social Media Networks with NodeXL: Insights from a Connected World" provides a step-by-step walkthrough for those who want to use NodeXL and explore the world of social network analysis. The language is clear and straightforward, which makes the key ideas easy to digest. Social network analysis is the application of social network theory, which is a meta theory stemming from multiple disciplines. Therefore, another section in the next edition of the book could be added to the book in order to provide a holistic perspective for those who want to explore both the theory and practice of social networking.

Online networked spaces are new environments that are employed for teaching and learning purposes. In today's world, most educational practices take place on these online networked spaces. The promise, potential and limitations of these spaces can be fully explored through new approaches such as social network analysis. In this sense, those who want to understand the dynamics of learning in these spaces can use this book as a prime reference. However, as an emerging area SNA and NodeXL updates itself, so the book should be revised accordingly.

Ultimately, the book serves as a fundamental reference for those who want to practice social network analysis. A wide range of readers who are interested in the study of social networking can benefit from this book to explore the world of networks, to x-ray network structures; and to identify, map, measure and visualize nodes and ties, as well as the overall network.

\section{References}

Castells, M. (2004). The network society: A cross cultural perspective. Northampton, MA: Edward Elgar.

Rainie, L., \& Wellman, B. (2012). Networked: The new social operating system. Cambridge, MA: MIT Press. 
Bozkurt, A., Akgun-Ozbek, E., \& Zawacki-Richter, O. (in press). Trends and patterns in massive open online courses: Review and content analysis of research on MOOCs (2008-2015). International Review of Research in Open and Distributed Learning, 18.

Scott, J. (2000). Social network analysis: A handbook (2nd ed.). Thousand Oaks, CA: Sage.

Hansen, D., Shneiderman, B., \& Smith, M. A. (2011). Analyzing social media networks with NodeXL: Insights from a connected world. Morgan Kaufmann.

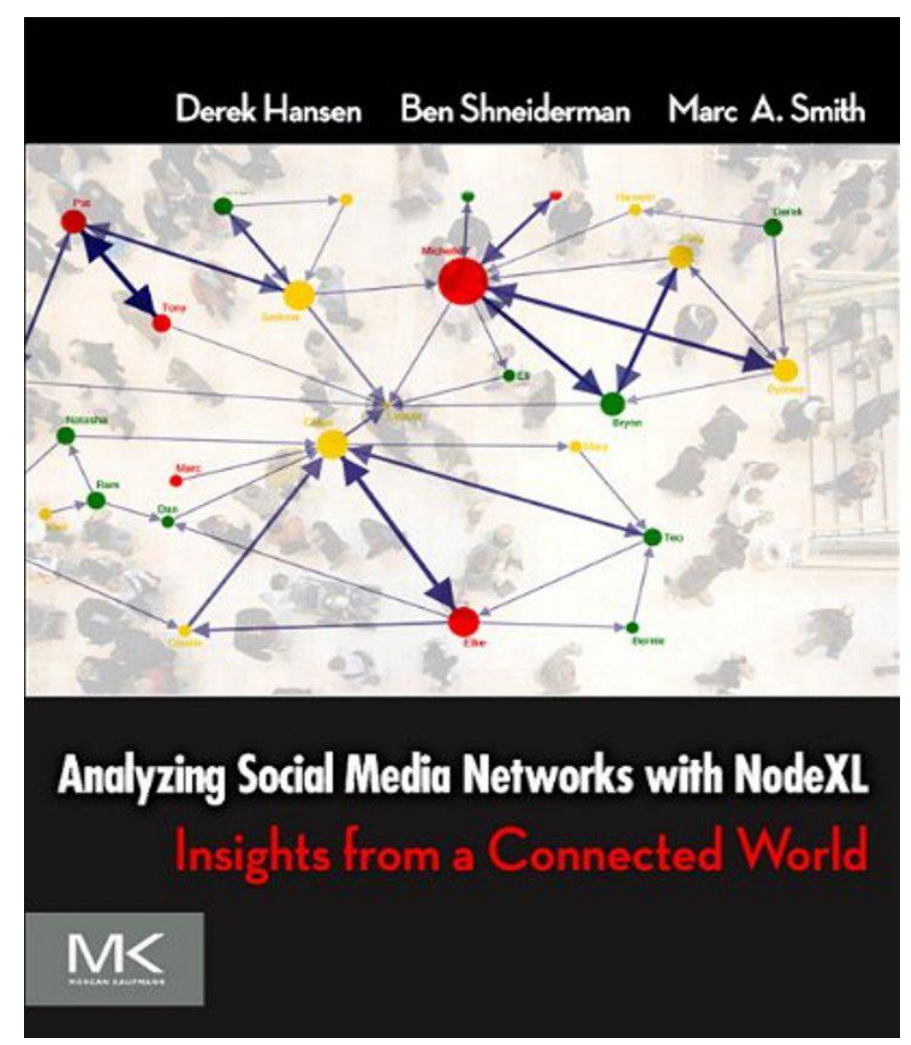

Correspondence: Aras Bozkurt, Ph.D., Learning Technologies Research and Development Unit, Open Education Faculty, Anadolu University, Yunus Emre Campus, Eskisehir, Turkey 